\title{
Reply to: Calcium/Citrate Ratio and Risk of Kidney Stone
}

\author{
Misan Lee ${ }^{1}$ Carmen Inés Rodriguez Cuellar ${ }^{1,2,3}$ Ravneet Nagra ${ }^{1}$ Peter Zhan Tao Wang ${ }^{4}$ \\ Vipin Bhayana ${ }^{5}$ Guido Filler $1,5,6,7$
}

1 Division of Paediatric Nephrology, Department of Paediatrics, Children's Hospital, Mexico City, Mexico

${ }^{2}$ Departamento de Nefrología Pediátrica, Instituto Nacional de Pediatría, Mexico City, Mexico

${ }^{3}$ Department of Pediatrics, Universidad Nacional Autónoma de México, Mexico City, Mexico

${ }^{4}$ Departments of Surgery, Division of Nephrology, and Schulich School of Medicine and Dentistry, University of Western Ontario, London, Ontario, Canada

${ }^{5}$ Departments of Pathology and Laboratory Medicine, Schulich School of Medicine and Dentistry, University of Western Ontario, London, Ontario, Canada

${ }^{6}$ Lilibeth Caberto Kidney Clinical Research Unit, London Health Sciences Centre, London, Ontario, Canada

${ }^{7}$ Departments of Medicine, Division of Nephrology, and Schulich School of Medicine and Dentistry, University of Western Ontario, London, Ontario, Canada

J Child Sci 2019;9:e91-e92.

We recently published our article entitled "Does the Urinary Calcium/Citrate (UCa/UCi) Ratio Add to the Diagnostic Workup of Children at Risk of Kidney Stones?" in your prestigious journal. ${ }^{1}$ We have received a letter to the editor by Beuy Joob and Viroj Wiwanikit. In that letter, the authors acknowledge that our findings are in accordance with the literature, especially the study by DeFoor et al. ${ }^{2}$ However, they also highlight that there is sexual variation for urine citrate. ${ }^{3}$ In adults and older adolescents, there clearly is a higher urinary citrate excretion in women as compared with that in men. ${ }^{3}$ Sex differences of the urinary citrate/creatinine ratio have since then been confirmed in adolescents. ${ }^{4}$ These sex differences start with the onset of puberty and may explain the higher prevalence of kidney stones in men. ${ }^{4}$ Interestingly, the substantial increase of nephrolithiasis in children and adolescents, however, is among adolescent girls. ${ }^{5,6}$

Our study by Lee $\mathrm{M}$ et al ${ }^{1}$ involved 56 males with a median (25th, 75 th percentile) age of $8(3,15)$ years and 41 females with a median age of $10(6.8,15)$ years, which was not statistically different ( $p=0.2720$, Mann Whitney U test). The details of the patients are listed in - Table 1. This means that most of the patients were prepubertal. As pointed out, the
Address for correspondence Guido Filler, MD, PhD, FRCPC, Medicine and Pathology and Laboratory Medicine, Children's Hospital, London Health Sciences Centre, University of Western Ontario, 800 Commissioners Road East, Rm B1-135, London ON, Canada, N6A 5W9 (e-mail: guido.filler@lhsc.on.ca). sex differences begin with the onset of puberty. ${ }^{4}$ The proposed cutoff for assessing the stone risk therefore holds in our patient cohort and the main conclusion that " $U_{C a} / U_{C i}$ rather than $U_{\mathrm{C}} / U_{\mathrm{Cr}}$ may be more predictive in the clinical setting when evaluating for nephrolithiasis" remains adequate as we did not observe any sex differences for the urinary citrate/creatinine ratio (-Fig. 1). Unfortunately, our cohort of patients was too small to perform a subanalysis of adolescents, and we did not routinely obtain the Tanner stage to precisely determine the onset of puberty. Therefore, we do acknowledge that more work is needed to assess the utility of the urinary $\mathrm{U}_{\mathrm{Ca}} / \mathrm{U}_{\mathrm{Ci}}$ as a predictor for nephrolithiasis or urolithiasis in pubertal adolescents. We agree with the conclusion in Joob and Wiwanitkit's letter to the editor that the sex variation should be kept in mind in interpreting $\mathrm{U}_{\mathrm{Ca}} / \mathrm{U}_{\mathrm{Ci}}$ in adolescents. We do see many adolescent girls with kidney stones who have normal $\mathrm{U}_{\mathrm{C}} / \mathrm{U}_{\mathrm{Cr}}$ but abnormal $\mathrm{U}_{\mathrm{Ca}} / \mathrm{U}_{\mathrm{Ci}}$. The reasons for the substantial increase of kidney stones in adolescent girls remain a main question for our ongoing research.

\section{Conflict of Interest}

None declared. received

June 25, 2019

accepted after revision

June 30, 2019
DOI https://doi.org/

10.1055/s-0039-1697922. ISSN 2474-5871.
Copyright (c) 2019 Georg Thieme Verlag License terms KG Stuttgart · New York 
Table 1 Patient characteristics and comparison of parameters

\begin{tabular}{|c|c|c|c|c|}
\hline Group & SF & NSF & Comparison & Test \\
\hline Number of patients & 51 & 46 & & \\
\hline Age (years, median and IQR) & $8(3,15)$ & $10(6.8,15)$ & 0.1755 & Mann Whitney \\
\hline Female (\%) & $19(37.3 \%)$ & $22(47.8 \%)$ & 0.3074 & Fisher's exact test \\
\hline Urinary citrate (mmol/L, median and IQR) & $1.55(0.95,2.32)$ & $1.675(0.79,3.13)$ & 0.7743 & Mann Whitney \\
\hline Urinary calcium (mmol/L, median and IQR) & $1.87(1.21,4.29)$ & $1.0(0.26,2.3)$ & 0.0021 & Mann Whitney \\
\hline Urinary sodium (mmol/L, median and IQR) & $77(30,121)$ & $107(48,154)$ & 0.0963 & Mann Whitney \\
\hline Urinary potassium (mmol/L, median and IQWR) & $42(28,101)$ & $48(19,80)$ & 0.9895 & Mann Whitney \\
\hline Urinary creatinine ( $\mu \mathrm{mol} / \mathrm{L}$, median and IQR) & $3.4(1.5,6.8)$ & $4.6(1.9,9.0)$ & 0.3878 & Mann Whitney \\
\hline Urinary oxalate $(\mu \mathrm{mol} / \mathrm{L}$, median and IQR) & $189(111,291)$ & $134(38,290)$ & 0.1438 & Mann Whitney \\
\hline Urinary urate ( $\mu \mathrm{mol} / \mathrm{L}$, median and IQR) & $1.9(1,5.7)$ & $2.3(1,12)$ & 0.2544 & Mann Whitney \\
\hline Urinary $\mathrm{pH}($ mean $\pm \mathrm{SD})$ & $6.6 \pm 0.91$ & $6.5 \pm 0.98$ & 0.7366 & t-test \\
\hline $\begin{array}{l}\text { Urinary specific gravity } \\
\text { (median and IQR) }\end{array}$ & $\begin{array}{l}1.010 \\
(1.005,1.020)\end{array}$ & $\begin{array}{l}1.015 \\
(1.005,1.020)\end{array}$ & 0.1842 & Mann Whitney \\
\hline $\begin{array}{l}\text { Urinary citrate/creatinine } \\
\text { (mmol/mmol, median and IQR) }\end{array}$ & $0.48(0.21,0.90)$ & $0.38(0.21,0.86)$ & 0.8784 & Mann Whitney \\
\hline $\begin{array}{l}\text { Urinary calcium/creatinine } \\
\text { (mmol/mmol, median and IQR) }\end{array}$ & $0.67(0.31,1.37)$ & $0.24(0.11,0.73)$ & 0.0029 & Mann Whitney \\
\hline $\begin{array}{l}\text { Urinary calcium/citrate } \\
\text { (mmol/mmol, median and IQR) }\end{array}$ & $1.30(0.73,2.78)$ & $0.68(0.29,1.83)$ & 0.0114 & Mann Whitney \\
\hline $\begin{array}{l}\text { Urinary sodium/potassium } \\
(\mathrm{mmol} / \mathrm{mmol}, \text { mean } \pm \mathrm{SD})\end{array}$ & $2.08 \pm 1.92$ & $2.50 \pm 1.36$ & 0.3185 & t-test \\
\hline
\end{tabular}

Abbreviations: IQR, interquartile range (25th and 75th percentiles); NSF, non-stone formers; SD, standard deviation, SF, stone formers.

Note: Statistically significant differences are in boldface. The comparison column represents the $p$-value, and in the test column, the test that was used is listed (based on the distribution and data type).

\section{Citrate to creatinine}

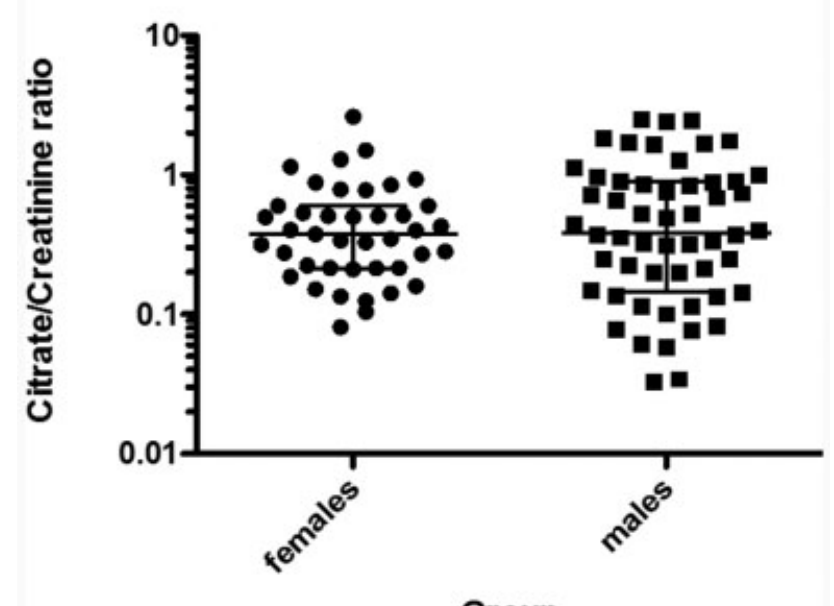

Group

Fig. 1 Comparison of urinary citrate/creatinine ratio in the aforementioned study. ${ }^{1}$ There was no significant difference between both sexes.

\section{References}

1 Lee M, Rodriguez Cuellar CI, Nagra R, Wang ZTP, Bhayana V, Filler G. Does the urinary calcium/citrate ratio add to the diagnostic workup of children at risk of kidney stones? A cross-sectional study. J Child Sci. 2019;9:e1-e6

2 DeFoor W, Jackson E, Schulte M, Alam Z, Asplin J. Calcium-tocitrate ratio distinguishes solitary and recurrent urinary stone forming children. J Urol 2017;198(02):416-421

3 Perry GM, Scheinman SJ, Asplin JR. Effects of sex on intraindividual variance in urinary solutes in stone-formers collected from a single clinical laboratory. PLoS One 2013;8(06):e53637

4 Kirejczyk JK, Porowski T, Konstantynowicz J, et al. Urinary citrate excretion in healthy children depends on age and gender. Pediatr Nephrol 2014;29(09):1575-1582

5 Edvardsson VO, Ingvarsdottir SE, Palsson R, Indridason OS. Incidence of kidney stone disease in Icelandic children and adolescents from 1985 to 2013: results of a nationwide study. Pediatr Nephrol 2018;33(08):1375-1384

6 Rodriguez Cuellar CI, Wang PZT, Freundlich M, Filler G. Educational review: role of the pediatric nephrologists in the work-up and management of kidney stones. Pediatr Nephrol 2019 